\title{
Research on the Damping Performance of Mining Highly Efficient Water-Retaining Colloidal Material Against the Spontaneous Combustion of Coal
}

\author{
Yongfei Jin ${ }^{1,2}$, Li Yan ${ }^{1,2^{*}}$, Yin Liu ${ }^{1,2}$, Chuansheng Li ${ }^{1,2}$ \\ ${ }^{1}$ School of Safety Science and Engineering, Xi'an University of Science and Technology, Xi'an 710000, China \\ ${ }^{2}$ National Mine Rescue Xi'an Research Centre, Xi'an 710054, China
}

Corresponding Author Email: 20120089024@stu.xust.edu.cn

https://doi.org/10.18280/acsm.450407

Received: 8 April 2021

Accepted: 25 July 2021

\section{Keywords:}

fire protection materials, sodium alginate, high hydrocolloid, coal spontaneous combustion

\begin{abstract}
In order to solve the shortcomings of the traditional mining anti-extinguishing gel material such as low strength and poor water retention, a high hydrocolloid antiextinguishing material was developed with sodium alginate and light calcium carbonate as the base material and gluconolactone as the retarder, which was mixed and reacted. The base material ratio of highly efficient water-retaining colloidal material for coal void filling was determined as $2 \% \mathrm{SA}+0.5 \% \mathrm{PCC}+1 \% \mathrm{GDL}$ with a moulding time of 4.5 min, while the base material ratio of highly efficient water-retaining colloidal material for extinguishing high temperature fires was $2.5 \% \mathrm{SA}+1 \% \mathrm{PCC}+1 \% \mathrm{GDL}$ with a moulding time of $2.5 \mathrm{~min}$. The highly efficient water-retaining colloidal material was found to reduce the concentration of signature gas and delay the characteristic temperature point and increase the activation energy of coal oxidation, which indicates that the highly efficient water-retaining colloidal material can effectively inhibit the spontaneous combustion process of coal at low temperature stage. Infrared spectroscopy experiments were conducted to investigate the microscopic resistance mechanism of the highly efficient water-retaining colloidal material, and the results showed that the highly efficient water-retaining colloidal material mainly reduce the activity of Ar-C-O-, COO-, $-\mathrm{CH} 3,-\mathrm{CH} 2$ and - $\mathrm{OH}$ in coal to inhibit the spontaneous combustion of coal.
\end{abstract}

\section{INTRODUCTION}

Coal has always been the main source of energy in the development of China, accounting for approximately $70 \%$ of the primary energy mix [1-4]. The development of industry depends on the supply of energy, therefore coal as a major energy source must strengthen the safety investment in the coal industry to ensure its long-term stable, healthy and sustainable development $[5,6]$. However, more than half of China's coal mines are at risk of natural fires, and fire accidents caused by coal spontaneous combustion account for more than $90 \%$ of all coal mine fires $[7,8]$.

So far, a variety of technical measures or materials have been used to prevent spontaneous combustion of coal, such as grouting [9], equalizing pressure ventilation [10], inert gas [11], inhibitor [12], foam [13, 14] and ionic liquid [15]. Grouting and fire suppression technology became the main means of mine fire suppression in the mid-20th century and has been used ever since [16]. Grouting for fire suppression is simple and inexpensive [17], but the slurry does not have stacking properties, making it difficult to seal and extinguish gaps or fire sources at higher locations, and the grouting material can develop a large number of fissures after water loss, which can easily form new air leakage channels [18, 19]. Wang [20] first proposed three-phase foam in 2004, and after Qin et al. [21] optimized and improved its performance to produce high-performance three-phase foam, it began to be widely used in mines gradually and achieved obvious excellent results. The three-phase foam is widely applicable, has good diffusivity, and combines sealing and inerting functions $[22,23]$, but the process is complex and costly, and the foam has a short duration of action and loses its fire prevention effect completely after water loss. Hao and Xie [24] comparatively studied the inhibition effect of inert gases $\mathrm{N}_{2}$ and $\mathrm{CO}_{2}$ on coal spontaneous combustion by means of a programmed warming test apparatus, and the results showed that both inert gases have flame retardant effect, and the effect of $\mathrm{CO}_{2}$ is better. However, the residence time of the inert gas in the designated area is short and difficult, the effect decreases significantly when the air leakage in the area is large, and it is difficult to have extinguishing properties for the residual flame of the negative combustion $[25,26]$. Fire retardant technology on the one hand through the negative catalytic effect of the material to inhibit coal oxidation, on the other hand, the retardant material will be sprayed on the surface of the coal body to generate a thin film, can reduce the contact area of coal oxygen from the physical aspects of the coal body to reduce the oxygen adsorption capacity, so as to achieve the effect of preventing spontaneous combustion of coal [27-29], but the retardant in the high temperature after the loss of water, its fire function will also be completely lost, and some retardant in the loss of water will promote the oxidation of coal spontaneous combustion. However, after water loss at high temperatures, the fire protection function will be completely lost, and some resistants will promote oxidative spontaneous combustion of coal after water loss, so the actual field application of resistants has certain limitations. 
The water in the colloidal material vaporises rapidly at high temperatures, taking away a large amount of heat and reducing the temperature of the coal. The residual colloidal shell can form a thin film covering the coal body, preventing coaloxygen contact and thus inhibiting the oxidation process of the coal body [28]; the incompletely dried colloidal body can fill the pores of the coal body and wrap the coal body, also isolating oxygen from the coal body and gradually weakening the oxidation reaction of the coal [30]. However, conventional colloidal fire protection technology suffers from high water loss of conventional colloidal material, harsh transport conditions of the base material and some materials can be hazardous to human health, which reduces the safety of the coal production process [31]. Therefore, it is imperative to research a new non-toxic, high-water colloidal fire protection material.

In this paper, a new high-water colloidal material was developed using sodium alginate and light calcium carbonate, additives commonly used in food, as the main ingredients and gluconolactone as the retarding agent, to improve the water utilisation and overcome the limitations of traditional colloidal material. The thermal stability test, programmed temperature rise test, thermogravimetric and infrared spectroscopic tests were also conducted to investigate the dampening performance of the high-water colloidal material in the process of spontaneous coal combustion and to summarise its fire prevention and extinguishing fundamentals. The research results provide new ideas for the prevention and control of coal spontaneous combustion in the field.

\section{MATERIAL PREPARATION AND PRINCIPLES}

\subsection{Materials and reagents}

In this paper, the base materials for the preparation of highly efficient water-retaining colloidal material include sodium alginate (SA), light calcium carbonate (PCC), glucono- $\delta$ lactone (GDL) and water, of which SA, as a natural polysaccharide, is non-toxic and harmless, raw materials are abundant and easy to obtain and inexpensive, and has a certain viscosity due to the phenomenon of polyanion in its aqueous solution. The main materials and physical diagrams are shown in Table 1, Table 2 and Figure 1.

Table 1. Main materials for the trial

\begin{tabular}{|c|c|c|c|}
\hline Raw materials & Molecular formula & Specifications & Manufacturers \\
\hline SA & $\left(\mathrm{C}_{6} \mathrm{H}_{7} \mathrm{NaO}_{6}\right)_{\mathrm{x}}$ & Food grade & Tian Tian seaweed Co., Ltd \\
\hline PCC & $\mathrm{CaCO}_{3}$ & Food grade & Xin Da food chemical Biotechnology \\
\hline GDL & $\mathrm{C}_{6} \mathrm{H}_{10} \mathrm{O}_{6}$ & Food grade & Henan Wan Bang Co., Ltd \\
\hline $\begin{array}{l}\text { Deionized water } \\
\text { Coal }\end{array}$ & $\mathrm{H}_{2} \mathrm{O}$ & $\begin{array}{l}\text { Homemade } \\
\text { anthracite }\end{array}$ & Shigetai Coal Mine \\
\hline
\end{tabular}

Table 2. Test instruments and specifications

\begin{tabular}{ccc}
\hline Instrument & Model & Manufacturers \\
\hline Electronic scale & JY12002 & Loki Company \\
Constant temperature water bath heater & DF-101S & Shanghai Kun Cheng Co., Ltd \\
Electric Blender & JJ-1 & Zhengzhou Feng Ke Co., Ltd \\
Stopwatch & D-8002 & Shenzhen Zhui Ri Electronic Technology Co., Ltd \\
Sample separation screen & $40-350$ mesh & Zhejiang Shangyu Dao Xu Zhu Instrument Factory \\
Jaw crusher & FW-200 & Shanghai Ke Heng Industrial Development Co., Ltd \\
Sample pulverizer & FM-3 & Shanghai Ke Heng Industrial Development Co., Ltd \\
Automatic coal quality analyzer & MAGEL-6700 & Henan Xin Chuang Co., Ltd \\
Synchronous thermal analyzer & STA449F3 & Netzsch AG \\
Fourier transform micro infrared spectrometer & Nicolet iN10\&iZ10 & Thermo Fisher \\
\hline
\end{tabular}

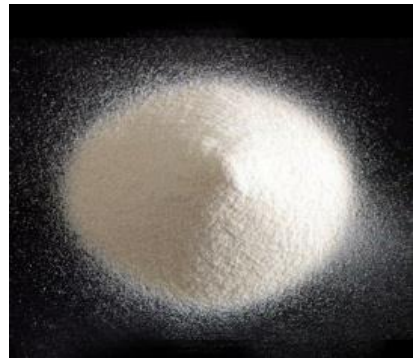

(a) SA

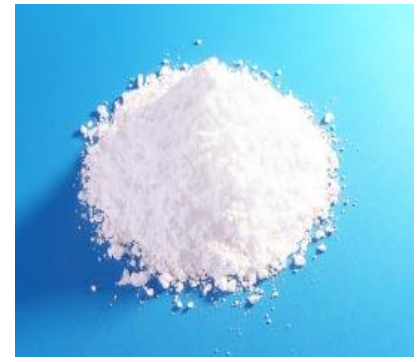

(b) PCC

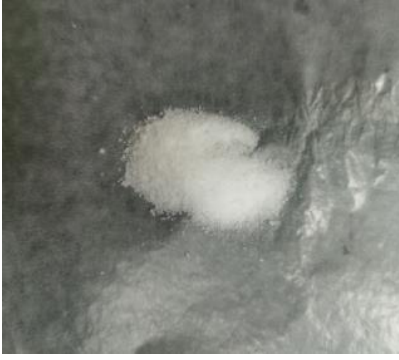

(c) GDL

Figure 1. Physical view of the material

\subsection{Principle of the test}

SA can form a stable cross-linking structure with $\mathrm{Ca}^{2+}$ in a certain temperature range. Free $\mathrm{Ca}^{2+}$ will replace $\mathrm{Na}^{+}$at the carboxyl group of SA solution, and the carboxyl group of the other chain is connected with $\mathrm{Ca}^{2+}$ again, finally forming a complete cross-linking structure. Because the carboxylic acid radicals at both ends of the crosslinking process can be connected first, the formed crosslinking structure is close to spherical and can wrap a large number of water molecules, so the crosslink has the characteristics of slow water release [32], so it is called highly efficient water-retaining colloidal material. 
The PCC-GDL was used to prepare the composite crosslinked system, using GDL to slowly release $\mathrm{H}^{+}$after dissolving in water, and the $\mathrm{H}+$ first reacted with $\mathrm{PCC}$ to slowly release calcium ions, and the released $\mathrm{Ca}^{2+}$ cross-linked with sodium alginate molecules to form an overall more uniform high- water colloidal material, avoiding the uneven structure of the high-water colloidal material caused by the rapid reaction of sodium alginate and calcium ions [33]. The formation mechanism is shown in Figure 2.

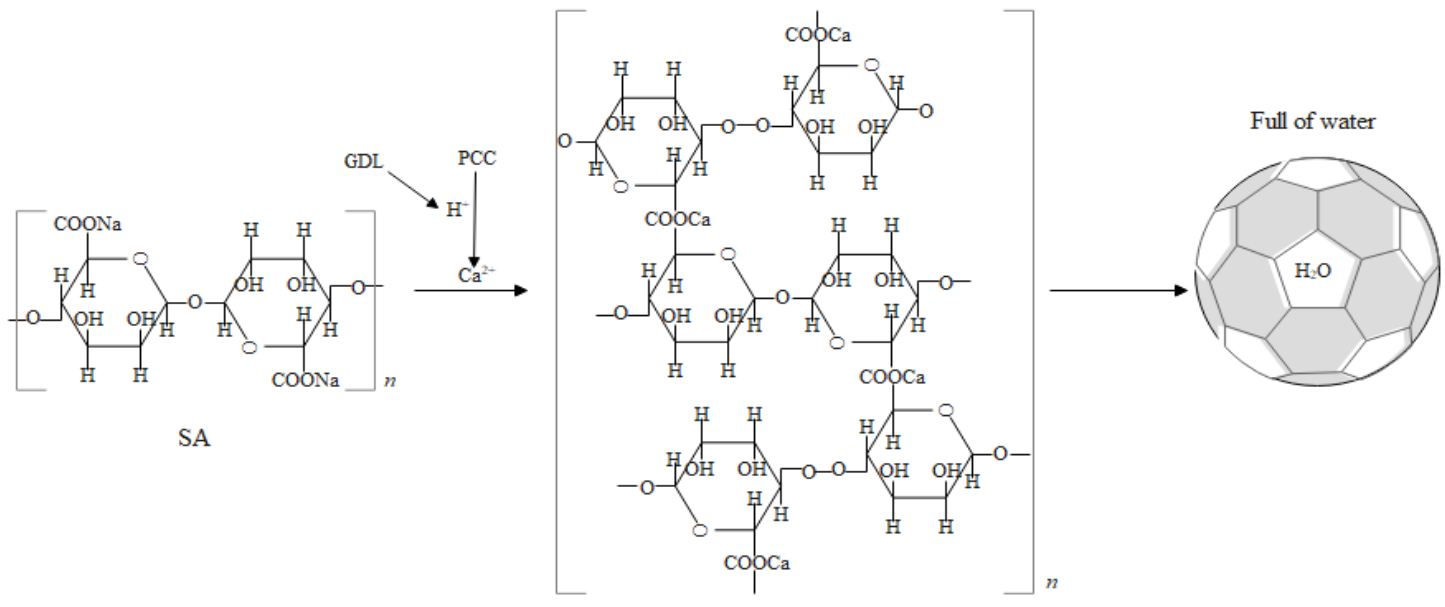

Figure 2. Mechanisms for the formation of highly hydrated colloidal material

\subsection{Material preparation}

According to the pre-test, when the SA dosing is less than $1 \%$ (the mass of water is $100 \mathrm{~g}$ ), the solution is not viscous because the viscosity is too low, while when the SA dosing reaches $3 \%$, the solution is too viscous and the liquidity is poor, and the pipeline is easy to cause plugging and other phenomena when conveying, so the SA solutions with the dosing of $1 \%, 1.5 \%, 2 \%$ and $2.5 \%$ are selected for the subsequent test, as shown in Figure 3.

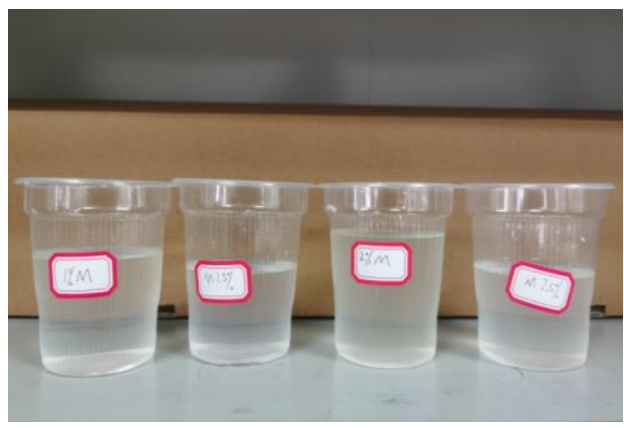

Figure 3. SA solution
Different masses of SA powder were weighed and added to the water slowly and uniformly, and an electric stirrer was used to stir at a constant speed during the process. The stirring was stopped when there were no large flocs in the solution and then left to stand at room temperature for about 2 to 3 hours until the SA was completely dissolved. After the SA solution was prepared, a certain amount of PCC and GDL mixture was first added and stirred thoroughly.

\subsection{Coal sample preparation}

Fresh coal samples were collected from the Shigetai coal mine and stored under seal. The coal samples were crushed under nitrogen protection and sieved to a particle size of 63$75 \mu \mathrm{m}$. The screened pulverised coal samples were unified in a vacuum drying oven. In order to prevent dry distillation of the coal samples and cracking of the coal properties under high temperature environment, the drying temperature was set to $50^{\circ} \mathrm{C}$ and dried at constant temperature for $6 \mathrm{~h}$. The MAGEL6700 fully automatic coal quality analyser was used to analyse the raw coal samples and the treated samples with $2.5 \% \mathrm{SA}+$ $1 \%$ PCC $+1 \%$ GDL added. The test results are shown in Table 3.

Table 3. Proximate analysis and ultimate analysis of pulverized coal

\begin{tabular}{ccccccccccc}
\hline \multirow{2}{*}{ Sample } & \multicolumn{4}{c}{ Proximate analysis (\%) } & \multicolumn{4}{c}{ Ultimate analysis (Wad/\%) } \\
& $\mathrm{M}_{\mathrm{ad}}$ & $\mathrm{A}_{\mathrm{ad}}$ & $\mathrm{V}_{\mathrm{ad}}$ & $\mathrm{FC}_{\mathrm{ad}}$ & $\mathrm{Q}_{\mathrm{gr}, \mathrm{d}} / \mathrm{MJ} \cdot \mathrm{kg}^{-1}$ & $\mathrm{C}$ & $\mathrm{H}$ & $\mathrm{O}$ & $\mathrm{N}$ & $\mathrm{S}$ \\
\hline Raw coal sample & 0.87 & 22.4 & 10.07 & 68.91 & 27.66 & 80.12 & 3.02 & 14.65 & 1.91 & 0.30 \\
Treated sample & 22.56 & 15.12 & 8.45 & 53.87 & 24.20 & 71.51 & 8.94 & 18.25 & 1.03 & 0.24 \\
\hline
\end{tabular}

\section{OPTIMIZATION OF BASE MATERIAL RATIO}

Highly efficient water-retaining colloidal material are used in mines for two main functions, one is to fill and plug leaks to reduce the probability of oxidative spontaneous combustion of coal, and the other is to extinguish and cool down abnormally hot areas in the mine. In order to achieve the desired filling or extinguishing effect of highly efficient water- retaining colloidal material in the target area, the determination and control of the forming time and water retention of highly efficient water-retaining colloidal material for fire prevention and extinguishing is extremely important.

\subsection{Forming time}

In this paper, the molding time of highly efficient water- 
retaining colloidal material was measured by bottle test. Firstly, put SA solutions of different concentrations into the test tube, and then add PCC and GDL of different dosages as required. After the three are added and stirred evenly, start timing, and then tilt the test tube at $45^{\circ}$ every 30 seconds until the position of highly efficient water-retaining colloidal material in the test tube does not move. The time used is the molding time of highly efficient water-retaining colloidal material.

When the SA concentration is $1 \%, 1.5 \%, 2 \%$ and $2.5 \%$, PCC and GDL with different dosage are added respectively, and the forming time of highly efficient water-retaining colloidal material is compared and observed. The test results are shown in Figure 4.

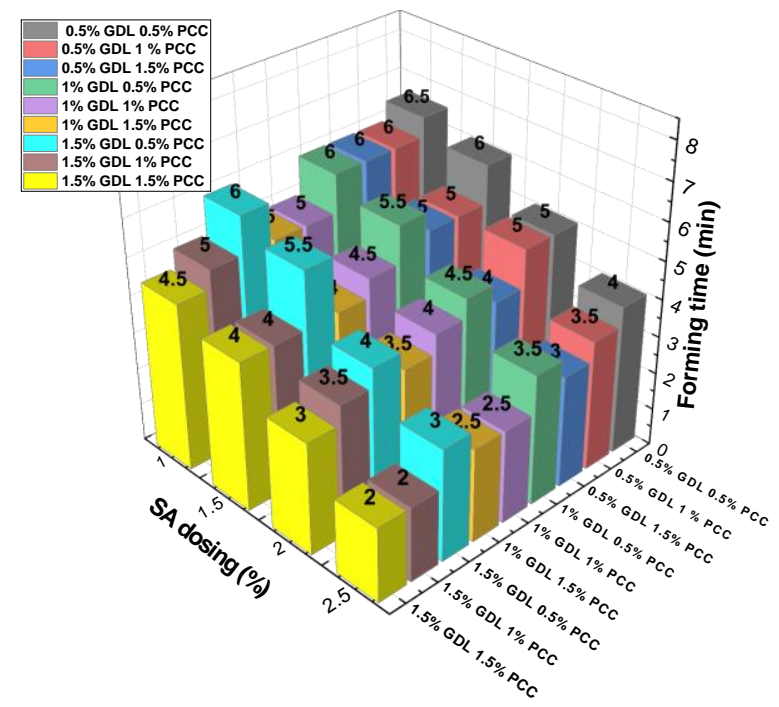

Figure 4. Forming time results graph

According to Figure 4, as the mass fraction of SA, PCC and GDL gradually increases, the internal macromolecular chains in the SA solution are more abundant and can bind $\mathrm{Ca}^{2+}$ faster and form a reticular cross-linked structure after the addition of PCC and GDL. The more GDL and PCC, the more $\mathrm{Ca}^{2+}$ can be released from PCC per unit time, making the molecular chains of sodium alginate and $\mathrm{Ca}^{2+}$ cross-linking easier, thus reducing the forming time of the high-hydrocolloid material. In addition, when the PCC dosing is the same, the overall pattern of variation is satisfied when the SA concentration is the independent variable, i.e. the forming time of the highly efficient water-retaining colloidal material decreases as the SA solution concentration increases.

\subsection{Water retention}

After the different proportions of capsules were prepared and placed at room temperature to observe the water loss at room temperature, the specific water loss and related analyses were as follows. The test results are shown in Figure 5.

When the concentration of SA was $1 \%$, the highly efficient water-retaining colloidal material with different base material ratios showed water precipitation, and the highest water loss rate was $43.2 \%(0.5 \% \mathrm{GDL}+0.5 \% \mathrm{PCC})$ and the lowest was $20.3 \%(1.5 \% \mathrm{GDL}+1.5 \%$ PCC) after $24 \mathrm{~h}$. This is due to the low concentration of SA at this time, the spacing between the molecular chains of sodium alginate is large, and the crosslinking reaction with $\mathrm{Ca}^{2+}$ results in a loose spatial network cross-linked structure. The spatial network cross-linked structure formed after the cross-linking reaction with $\mathrm{Ca}^{2+}$ was loose, resulting in water molecules escaping more easily from the cross-linked structure and poor water retention. The number of molecular chains increases with the concentration of SA and the cross-linked structure becomes more dense, thus improving the water retention effect of the high-water colloidal material.

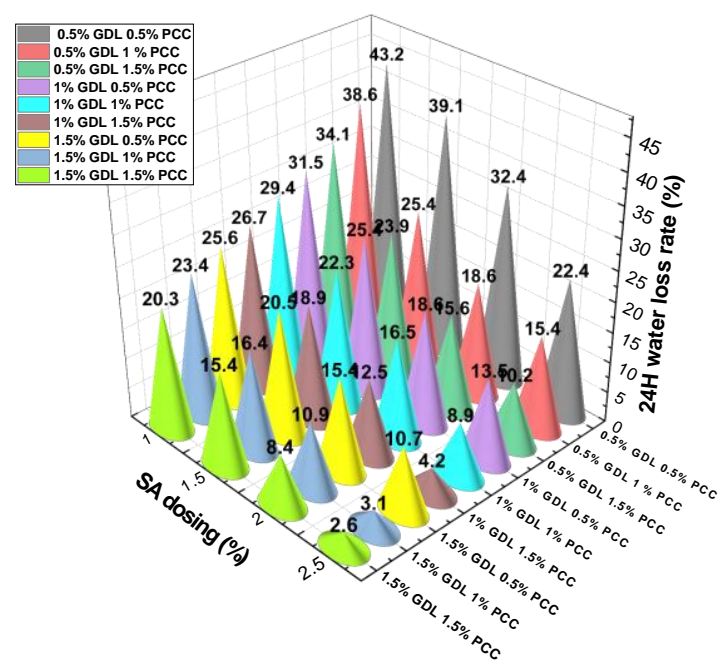

Figure 5. Graph of water loss rate results

\subsection{Discussion of results}

A comprehensive comparison of the forming time, water retention and characterization of the highly efficient waterretaining colloidal material shows that the water retention and strength of the capsules are relatively poor due to the SA concentration being below $2 \%$. When used as a void filling material in coal bodies, highly efficient water-retaining colloidal material are required to have good water retention and fluidity so that they can penetrate deeper into the crevices of the coal body and cover more of the surface area of the coal body within a certain period of time. When used to extinguish high temperature fires, highly efficient water-retaining colloidal material should be able to form more quickly after reaching the fire source, thus inhibiting the spread of the fire in the first instance. Therefore, when combined with the requirements of mine fire fighting conditions on the performance of highly efficient water-retaining colloidal material, as well as economic considerations, the base material ratio of highly efficient water-retaining colloidal material for coal void filling is: $2 \% \mathrm{SA}+0.5 \% \mathrm{PCC}+1 \% \mathrm{GDL}$, forming time $4.5 \mathrm{~min}$; when used to extinguish high temperature fires, the base material ratio of highly efficient water-retaining colloidal material is $2.5 \% \mathrm{SA}+1 \% \mathrm{PCC}+1 \%$ GDL, forming time $2.5 \mathrm{~min}$

\section{RESISTANCE STUDIES}

\subsection{Indicator gas resistivity testing}

Two samples of $80 \mathrm{~g}$ each were selected, one without treatment and the other with $8 \mathrm{~g}$ of highly efficient waterretaining colloidal material, and subjected to a programmed temperature rise test, with the test temperature range set at $30^{\circ} \mathrm{C}$ to $170^{\circ} \mathrm{C}$, the gas atmosphere set to standard air, the flow rate set to $50.0 \mathrm{~mL} / \mathrm{min}$ and the rate of rise set to $0.3^{\circ} \mathrm{C} / \mathrm{min}$. A gas sample was taken every $10^{\circ} \mathrm{C}$ and subjected to 
Chromatographic gas analysis. The results for the marker gases $\mathrm{CO}$ and $\mathrm{C}_{2} \mathrm{H}_{4}$ are shown in Figure 6 .

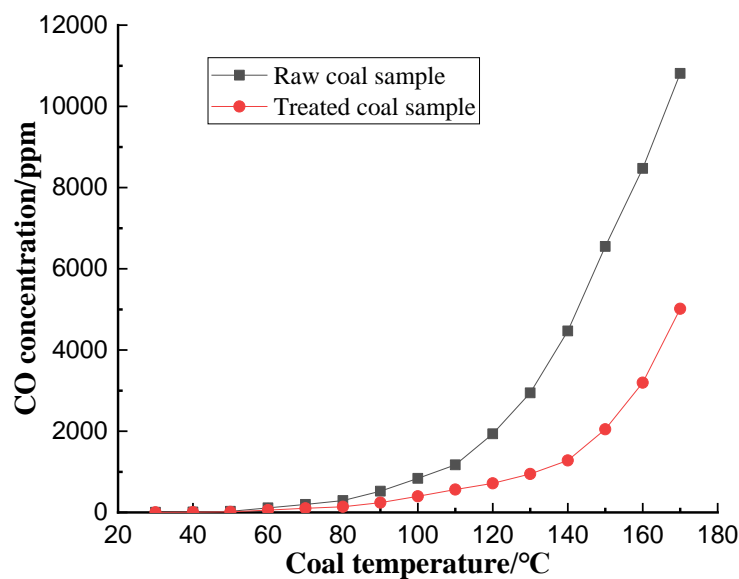

a) $\mathrm{CO}$ concentration

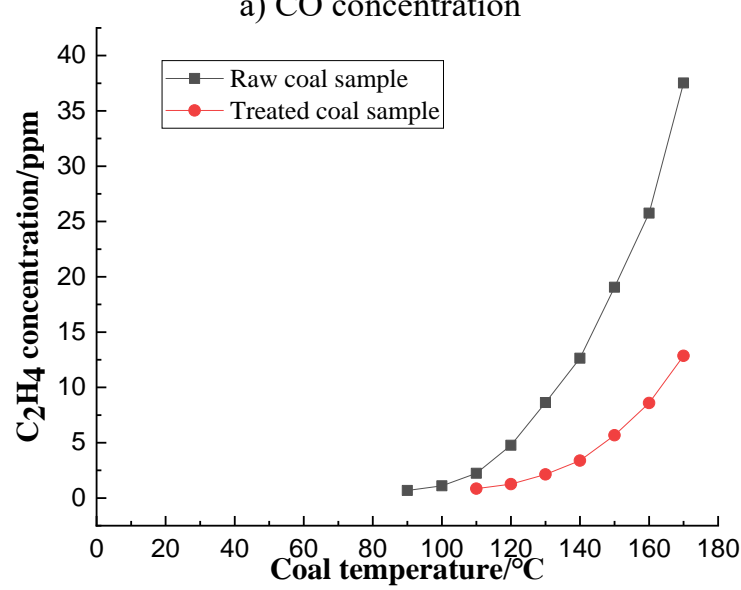

b) $\mathrm{C}_{2} \mathrm{H}_{4}$ concentration

Figure 6. Graph of changes in indicator gases

The addition of highly efficient water-retaining colloidal material to the coal sample, due to the highly efficient waterretaining colloidal material contains more water, in the process of following the coal sample warming highly efficient waterretaining colloidal material will take away most of the heat by way of water evaporation, thus the coal body itself is slowed down the rate of warming, the amount of $\mathrm{CO}$ production decreased, $\mathrm{C}_{2} \mathrm{H}_{4}$ generation temperature point is increased and the amount of production decreased. At the same time, the highly efficient water-retaining colloidal material can wrap part of the coal body to reduce the coal oxygen contact area and also play a role in inhibiting the heating of coal spontaneous combustion, so the highly efficient waterretaining colloidal material can play an effective role in the oxidation process of coal spontaneous combustion.

The barrier properties of highly efficient water-retaining colloidal material vary at different stages of the coal spontaneous combustion process, but the general trend is that the barrier properties between the critical temperature and the dry cracking temperature are greater than the barrier properties before the critical temperature. This reduces the rate and degree of oxidation.

\subsection{Characteristic temperature and activation energy studies}

\subsubsection{Thermogravimetric tests}

Two samples were taken, both weighing $10 \mathrm{mg}$, one without treatment and the other with $1 \mathrm{mg}$ of a $2 \%$ SA highly efficient water-retaining colloidal material. The two samples were then spread evenly on the crucible, and $5 \mathrm{ml} / \mathrm{min}$ of air was passed through the crucible, and the heating rate was set at $5 \mathrm{~K} / \mathrm{min}$. The TG-DTG curves of the coal samples were obtained by processing the data using origin software, and the five characteristic temperature points of the original coal samples and the treated samples were determined according to the classification of characteristic temperature points, and the results are shown in Figure7 and Figure 8.

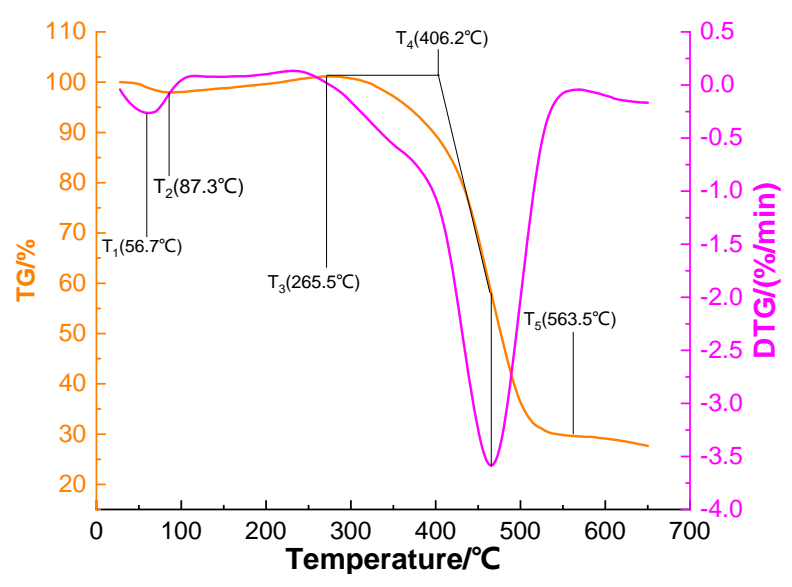

Figure 7. TG-DTG curve of raw coal sample

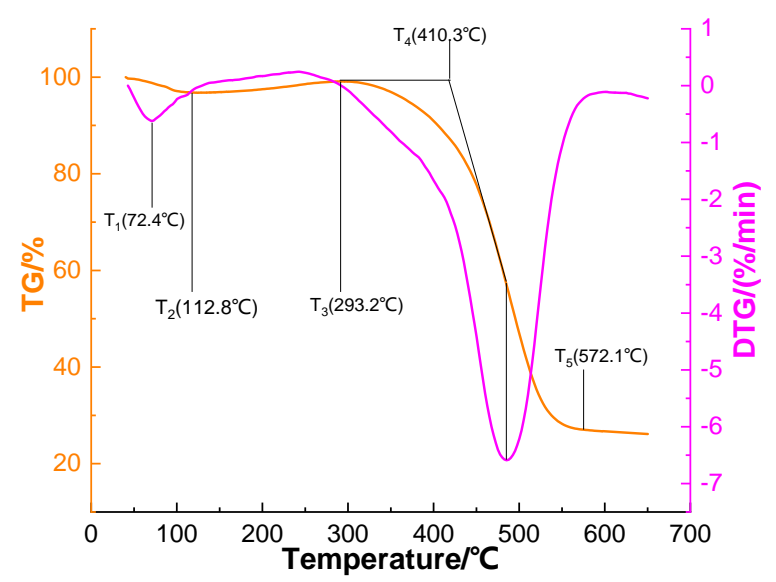

Figure 8. TG-DTG curve of treated sample

Compared with the raw coal sample, the critical temperature $\mathrm{T}_{1}$ of the treated sample is delayed by $15.7^{\circ} \mathrm{C}$. In this low temperature stage, the highly efficient water-retaining colloidal material mainly wraps the coal sample to reduce the coal oxygen composite area of the coal sample and inhibit the coal spontaneous combustion. As the highly efficient waterretaining colloidal material contains a large amount of water, with the temperature rising, the oxidation reaction will begin when the water in the plateau coal sample evaporates, and the treated sample can still take away the heat with the help of the evaporation of water in the highly efficient water-retaining colloidal material. Compared with the raw coal sample, the dry crack temperature $T_{2}$ of the treated sample is delayed by 25.5 degrees. At the stage of dry crack temperature $T_{3}$, in the early stage, the highly efficient water-retaining colloidal material still has a certain amount of water, which can absorb heat and take away heat, but the water loss rate will be accelerated. Therefore, when reaching the T3 temperature point, the temperature difference between the two samples is not 
significantly increased compared with $\mathrm{T}_{2}$. At the later $\mathrm{T}_{4}$ and $\mathrm{T}_{5}$ temperature points, there is little difference between the treated sample and the raw coal sample. At this time, the highly efficient water-retaining colloid material has completely lost water and shrunk, and the temperature is high. At this time, the highly efficient water-retaining colloid material basically loses its function as an organic polymer firefighting material.

\subsection{2 oxidation kinetics analysis}

In the process of coal oxidation and temperature rise, a certain activation energy is required. Only when the activation energy meets the energy required for coal oxidation reaction can it promote the further oxidation of coal [34], and the activation energy required for coal oxidation also represents the difficulty of coal oxidation reaction. The greater the activation energy, the more difficult it is to oxidize coal [35]. The activation energy during coal oxidation can be obtained by thermal analysis technology combined with oxidation kinetics method, so as to test the inhibition ability of highly efficient water-retaining colloidal material.

In the non isothermal experimental process in thermal equilibrium, the mass of the sample is regarded as a function of temperature. According to Arrhenius formula [36] and law of mass action, the decomposition rate of the sample can be expressed as:

$$
\begin{gathered}
\frac{d \alpha}{d t}=k f(\alpha) \\
k=A \exp \left(\frac{-E}{R T}\right)
\end{gathered}
$$

where: $k$ is Arrhenius rate constant $\left(\mathrm{min}^{-1}\right) ; E$ is the activation energy of the reaction $\left(\mathrm{KJ} \cdot \mathrm{mol}^{-1}\right) ; R$ is the gas constant, $R=8.414 \mathrm{Jmol}^{-1} \cdot \mathrm{K}^{-1} ; A$ is the frequency factor $\left(\mathrm{min}^{-1}\right) ; T$ is the absolute temperature $(\mathrm{K})$.

The form of $f(\alpha)$ depends on the type of reaction or reaction mechanism. It is generally assumed that $f(\alpha)$ has nothing to do with temperature $T$ and reaction $t$, but only with reaction degree $\alpha$. The heating rate $\beta$ can be expressed as:

$$
\beta=\frac{d T}{d t}
$$

Substitute (2) and (3) into (1) and rearrange the formula:

$$
\frac{d \alpha}{d T}=\frac{A}{\beta} \exp \left(\frac{-E}{R T}\right) f(\alpha)
$$

The integral form of equation (4) can be expressed as:

$$
G(\alpha)=\int_{0}^{\alpha} \frac{d \alpha}{f(\alpha)}=\frac{A}{\beta} \int_{T_{0}}^{T} \exp \left(\frac{-E}{R T}\right) d T
$$

Coats Redfern integral formula [37] is adopted:

$$
\ln \left[\frac{G(\alpha)}{T^{2}}\right]=\ln \frac{A R}{\beta E}-\frac{E}{R T}
$$

Therefore, $\ln \left[\frac{G(\alpha)}{T^{2}}\right]$ has a linear relationship with $\frac{1}{T}$, $\ln \left[\frac{G(\alpha)}{T^{2}}\right]$ is the y-axis, $\frac{1}{T}$ is the $\mathrm{x}$-axis, and it is fitted. The slope of the fitting line is $\frac{-E}{R}$, so the activation energy $E$ can be solved.

\begin{tabular}{|c|c|c|c|}
\hline $\begin{array}{l}\text { Function } \\
\text { Number }\end{array}$ & Function Name & $\begin{array}{c}\text { Differentiation } \\
f(\alpha)\end{array}$ & 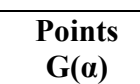 \\
\hline 1 & $\begin{array}{l}\text { Phase interface } \\
\text { reactions }\end{array}$ & 1 & $\alpha$ \\
\hline 2 & $\begin{array}{l}\text { Primary } \\
\text { chemical } \\
\text { reactions }\end{array}$ & $1-\alpha$ & $-\ln (1-\alpha)$ \\
\hline 3 & $\begin{array}{l}\text { Secondary } \\
\text { chemical } \\
\text { reactions }\end{array}$ & $(1-\alpha)^{3 / 2}$ & $\begin{array}{c}2 \ln (1-\alpha)^{-} \\
1 / 2-2\end{array}$ \\
\hline 4 & $\begin{array}{l}\text { Tertiary } \\
\text { chemical } \\
\text { reactions }\end{array}$ & $(1-\alpha)^{2}$ & $(1-\alpha)^{-1}-1$ \\
\hline 5 & $\begin{array}{l}\text { The power } \\
\text { function rule }\end{array}$ & $1 / 2 \alpha$ & $\alpha^{2}$ \\
\hline 6 & Valens equation & {$[1-\ln (1-\alpha)]^{-1}$} & $\begin{array}{c}(1-\alpha) \ln (1- \\
\alpha)+\alpha\end{array}$ \\
\hline 7 & G-B equation & $3 / 2\left[(1-\alpha)^{-1 / 3}\right]^{-1}$ & $\begin{array}{c}(1-2 \alpha / 3)- \\
(1-\alpha)^{2 / 3}\end{array}$ \\
\hline
\end{tabular}

The oxidative spontaneous combustion process of coal is a gas-solid two-phase reaction [38], and common mechanistic function models are shown in Table 4.

Table 4. Commonly used mechanistic functions for gas-solid reactions

This section focuses on the resistances of highly efficient water-retaining colloidal material prior to the dry cracking temperature of the coal body, so by using the different basis functions described above for the two stages $T_{0}$ to $T_{2}$ and $T_{2}$ to $\mathrm{T}_{3}$, respectively, the values of $\mathrm{E}$ and $\mathrm{R}^{2}$ are obtained as shown in Tables 5 and 6.

Table 5. E and ln A calculated by different mechanism functions in $\mathrm{T}_{0} \sim \mathrm{T}_{2}$ stages

\begin{tabular}{ccccccc}
\hline \multirow{2}{*}{ Function Number } & \multicolumn{2}{c}{ Raw coal sample } & \multicolumn{3}{c}{ Treated sample } \\
& $\mathrm{E}$ & $\ln \mathrm{A}$ & $\mathrm{R}^{2}$ & $\mathrm{E}$ & $\ln \mathrm{A}$ & $\mathrm{R}^{2}$ \\
\hline 1 & 26.2 & -6.4 & 0.8 & 44.3 & -0.7 & 0.87 \\
2 & 29.8 & -3.1 & 0.95 & 41.8 & 0.6 & 0.98 \\
3 & 32.6 & -0.7 & 0.92 & 71.8 & 1.4 & 0.94 \\
4 & 44.5 & 2 & 0.88 & 91.6 & 2.9 & 0.89 \\
5 & 53 & 1.5 & 0.84 & 96.4 & 2.5 & 0.89 \\
6 & 57.3 & 2.6 & 0.87 & 113.1 & 3.6 & 0.92 \\
7 & 68.1 & 1.8 & 0.89 & 108.6 & 2.8 & 0.93 \\
\hline
\end{tabular}

Table 6. E and ln A calculated by different mechanism functions in $\mathrm{T}_{2} \sim \mathrm{T}_{3}$ stages

\begin{tabular}{ccccccc}
\hline \multirow{2}{*}{ Function Number } & \multicolumn{3}{c}{ Raw coal sample } & \multicolumn{3}{c}{ Treated sample } \\
& $\mathrm{E}$ & $\ln \mathrm{A}$ & $\mathrm{R}^{2}$ & $\mathrm{E}$ & $\ln \mathrm{A}$ & $\mathrm{R}^{2}$ \\
\hline 1 & 59.5 & 12.3 & 0.8 & 28.2 & -3.1 & 0.91 \\
2 & 66.9 & 0.7 & 0.96 & 74.6 & 1.8 & 0.97 \\
3 & 78.3 & 36 & 0.94 & 62.7 & 9.8 & 0.93 \\
4 & 82.6 & 49 & 0.91 & 80.8 & 16.6 & 0.92 \\
5 & 85.7 & 39.4 & 0.82 & 65.4 & 8.7 & 0.93 \\
6 & 92.9 & 46.4 & 0.87 & 74.9 & 11.7 & 0.96 \\
7 & 105.1 & 44 & 0.87 & 77.5 & 11.4 & 0.92 \\
\hline
\end{tabular}

By selecting different basis functions for calculation and comparison, the first order chemical reaction mechanism function was preferred for the calculation of activation energy. 
The results of fitting the kinetic curves of the coal samples at different temperature stages are shown in Figure 9, and the activation energies of the coal samples in the untreated case and after the addition of highly efficient water-retaining colloidal material for the corresponding stages are derived as shown in Table 7.

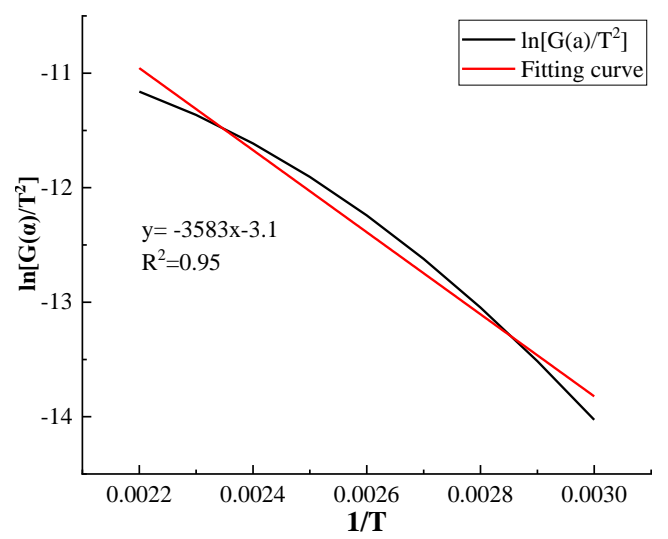

a) Kinetic curves for raw coal samples at $T_{0} \sim T_{2}$

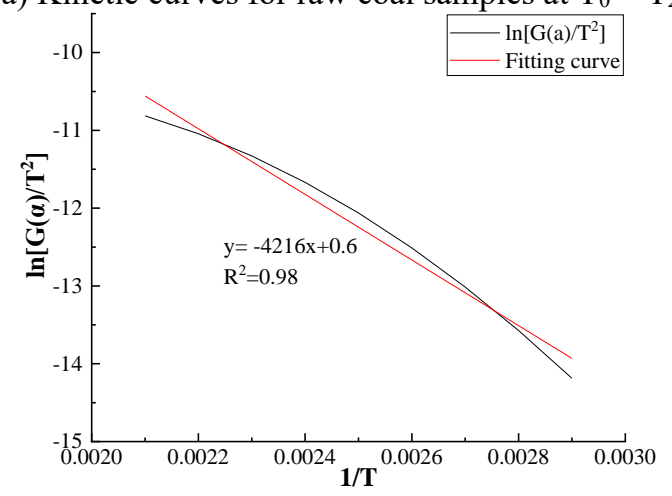

b) Kinetic curves for treated sample at $T_{0} \sim T_{2}$

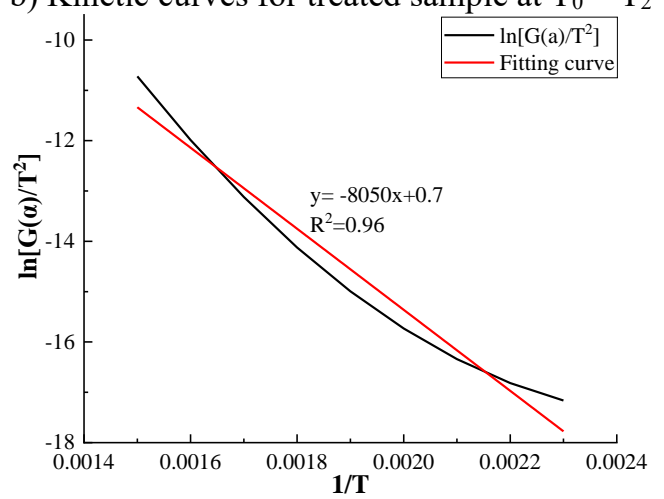

c) Kinetic curves for raw coal samples at $T_{2} \sim T_{3}$

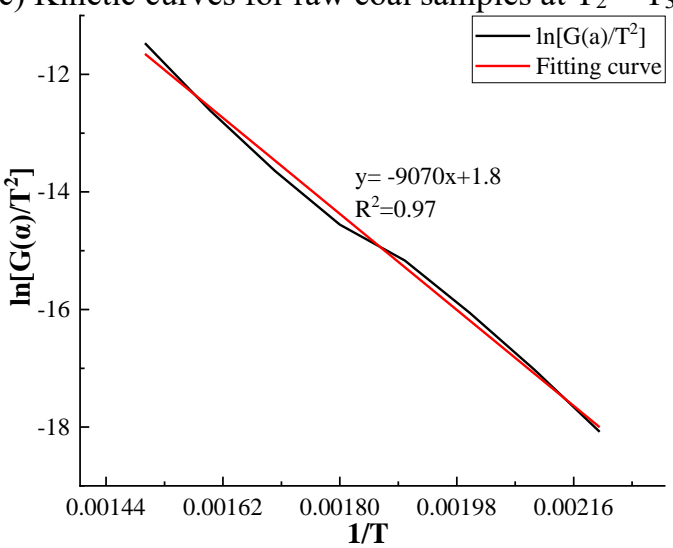

d) Kinetic curves for treated sample at $T_{2} \sim T_{3}$

Figure 9. Kinetic curves for raw and treated coal samples at $\mathrm{T} 0 \sim \mathrm{T} 3$
Table 7. Calculation of activation energy of coal samples at different stages $\left(\mathrm{KJ} \cdot \mathrm{mol}^{-1}\right)$

\begin{tabular}{ccc}
\hline Coal samples & $\mathbf{T}_{\mathbf{0}} \sim \mathbf{T}_{\mathbf{2}}$ & $\mathbf{T}_{\mathbf{2}} \sim \mathbf{T}_{\mathbf{3}}$ \\
\hline Raw coal sample & 29.8 & 66.9 \\
Treated sample & 35.1 & 75.4 \\
Increased activation energy & 5.3 & 8.5 \\
\hline
\end{tabular}

According to Table 7, the activation energies of the raw coal samples in the weight loss and oxygen uptake weight gain stages were significantly different, and the value of the activation energy required increased as the reaction proceeded. After the addition of highly efficient water-retaining colloidal material, the activation energy of both stages also changed, where the activation energy of T0 T 2 stage increased by 5.3 $\mathrm{KJ} \cdot \mathrm{mol}^{-1}$, and the activation energy of $\mathrm{T}_{2} \sim \mathrm{T}_{3}$ stage increased from the original $66.9 \mathrm{KJ} \cdot \mathrm{mol}^{-1}$ to $75.4 \mathrm{KJ} \cdot \mathrm{mol}^{-1}$, indicating that the highly efficient water-retaining colloidal material played a stable blocking effect, in addition, when the temperature of the coal body exceeded the dry cracking temperature, its oxidative spontaneous combustion capacity has become very strong, so the most effective time period for materials that inhibit coal spontaneous combustion is still to control coal spontaneous combustion at low temperatures. Comparing the activation energy of the raw and treated coal samples at both stages, the highly efficient water-retaining colloidal material can exert a better dampening effect before the dry cracking temperature of the coal.

\subsection{Effect of highly efficient water retaining colloidal material on functional groups in coal}

Studies on the spontaneous combustion of coal have shown that the action of functional groups of varying nature present in the molecular structure of coal is a fundamental factor in the oxidative warming and hence spontaneous combustion of coal [39]. In this experiment, the changes in the functional groups of the selected test coal samples at different temperatures were investigated and analysed.

Six samples of $50 \mathrm{~g}$ each, three without treatment and three with $5 \mathrm{~g}$ of highly efficient water-retaining colloidal material in the ratio of $2 \% \mathrm{SA}+0.5 \% \mathrm{PCC}+1 \% \mathrm{GDL}$, were heated at $40^{\circ} \mathrm{C}, 80^{\circ} \mathrm{C}$ and $120^{\circ} \mathrm{C}$ for $12 \mathrm{~h}$. After heating, the six samples were ground using a mortar and pestle and scanned using an infrared spectrometer with a wave number of $4000 \sim 500 \mathrm{~cm}^{-1}$, resolution $4 \mathrm{~cm}^{-1}, 32 \mathrm{scans} / \mathrm{sec}$. The IR spectra of the raw and treated coal samples were fitted to the peaks using origin software, where the peaks of the oxygen-containing functional groups and hydroxyl groups are shown in Figures 10-11.

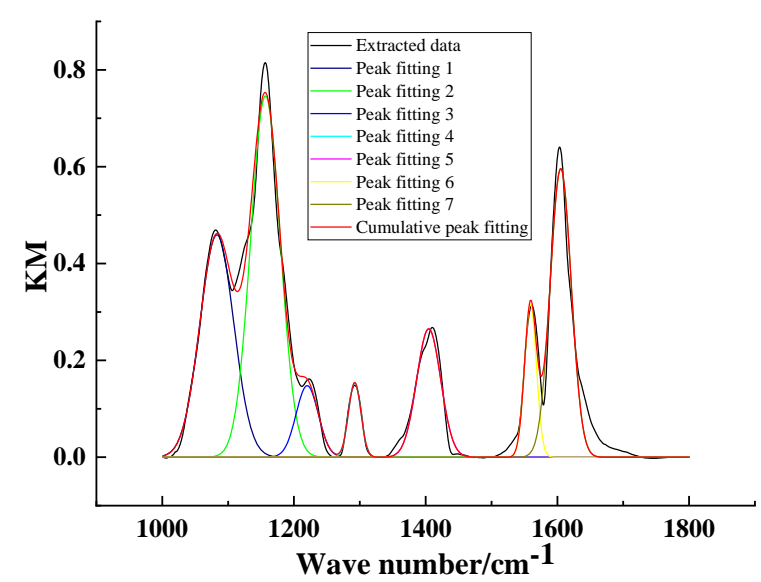

(a) $40^{\circ} \mathrm{C}$ treated sample 


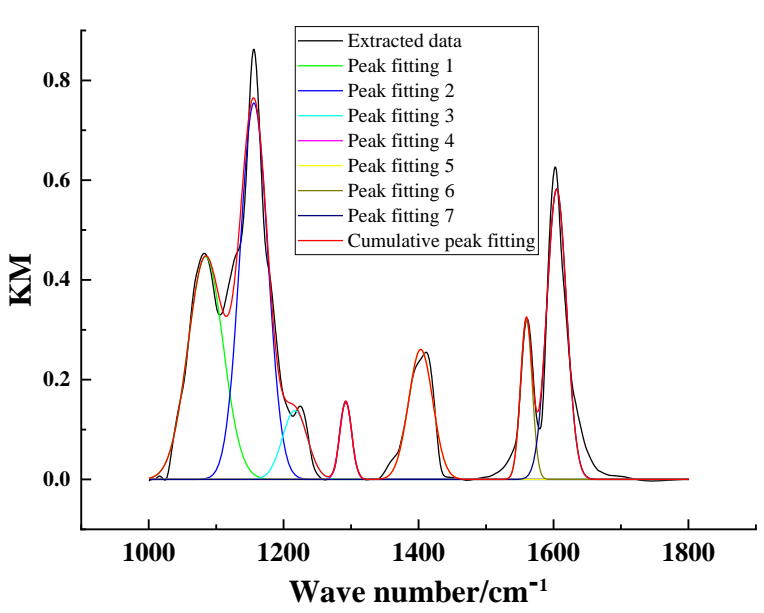

(b) $40^{\circ} \mathrm{C}$ raw coal sample

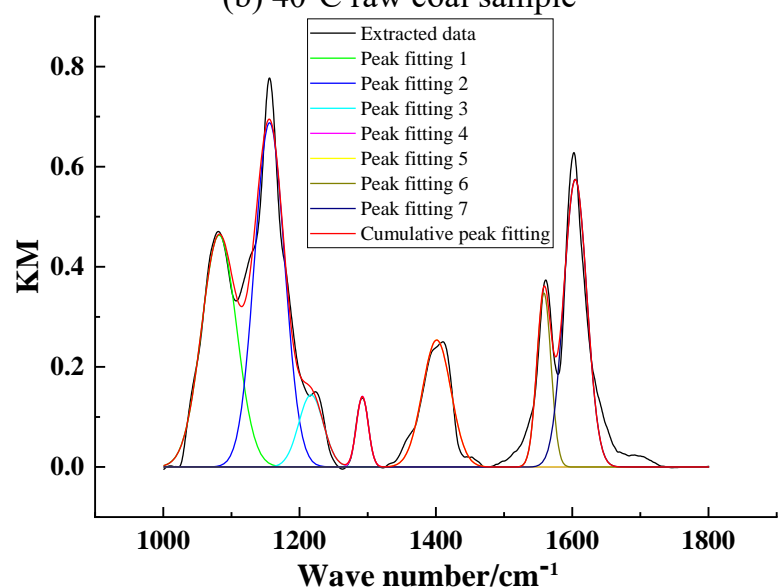

(c) $80^{\circ} \mathrm{C}$ treated sample

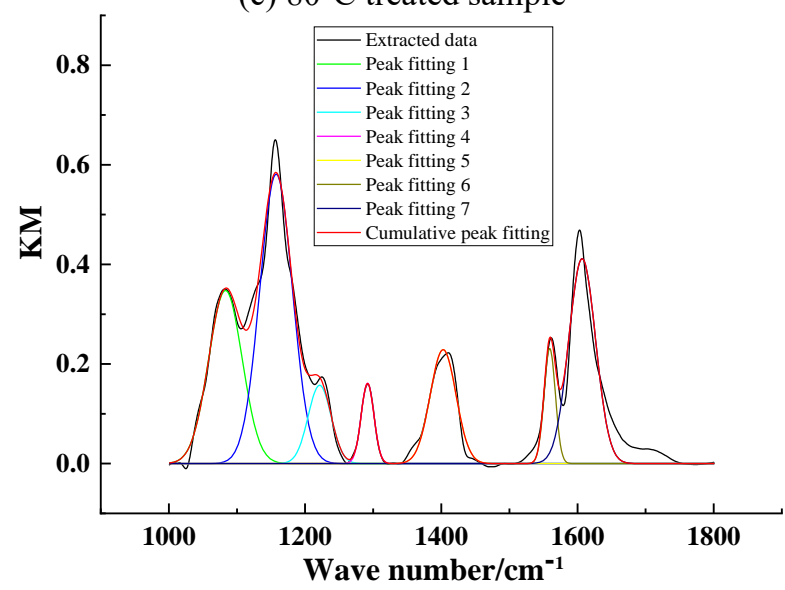

(d) $80^{\circ} \mathrm{C}$ raw coal sample

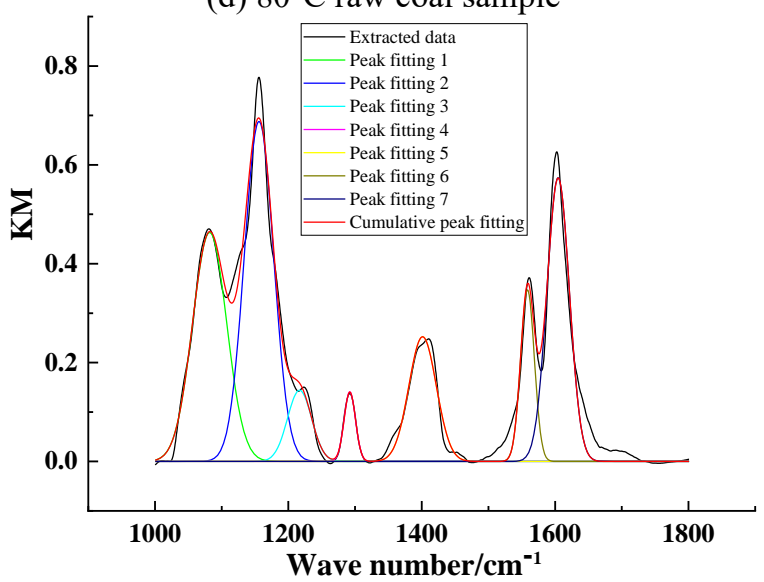

(e) $120^{\circ} \mathrm{C}$ treated sample

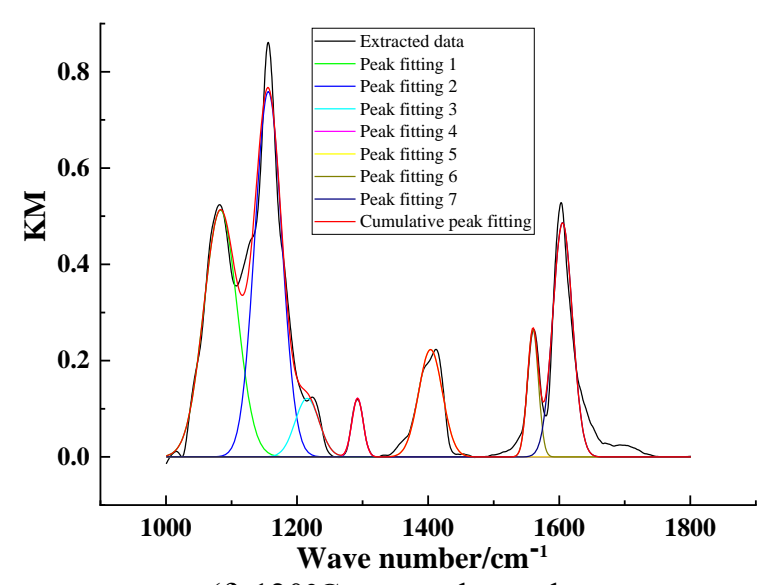

(f) $120^{\circ} \mathrm{C}$ raw coal sample

Figure 10. Fitting of oxygen-containing functional group peaks

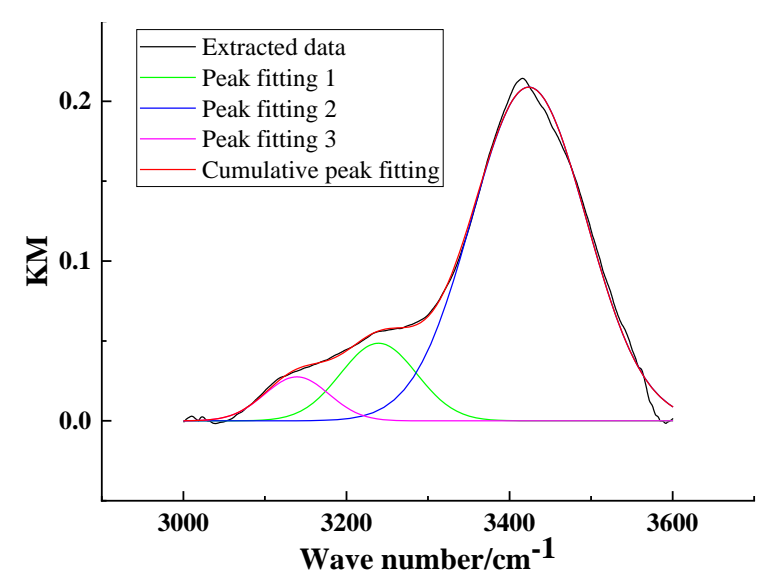

(a) $40^{\circ} \mathrm{C}$ treated sample

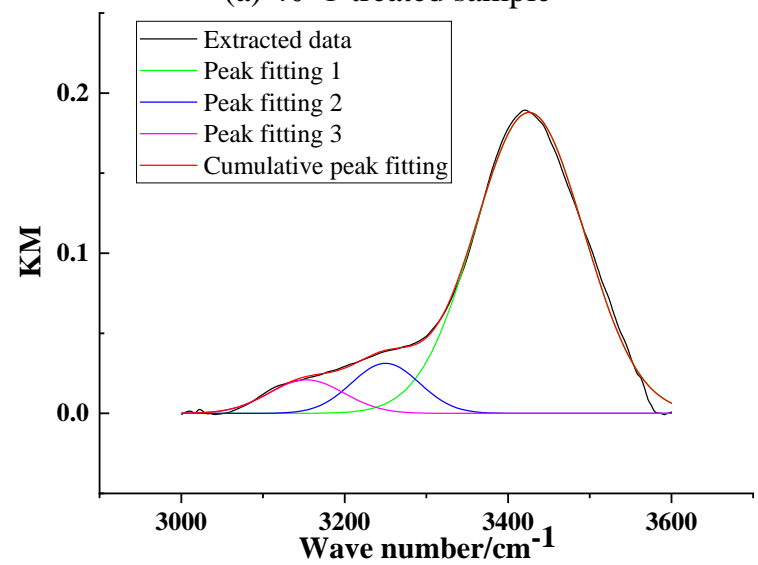

(b) $40^{\circ} \mathrm{C}$ raw coal sample

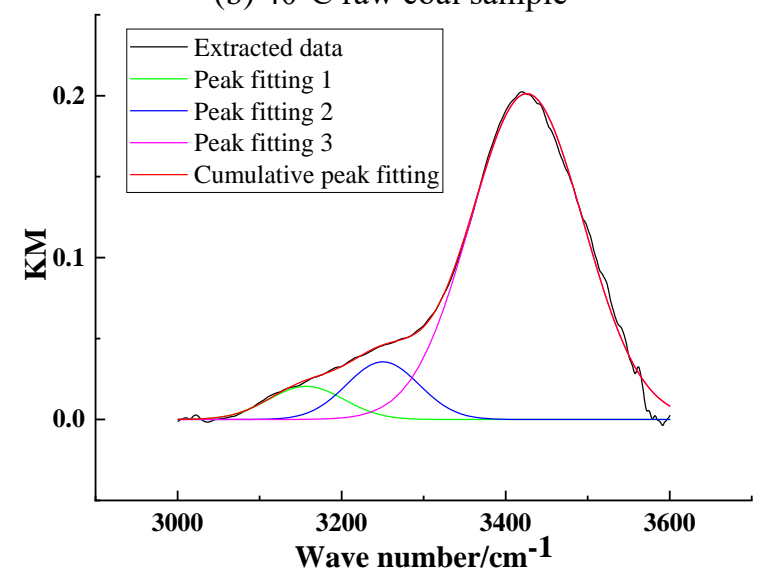

(c) $80^{\circ} \mathrm{C}$ treated sample 


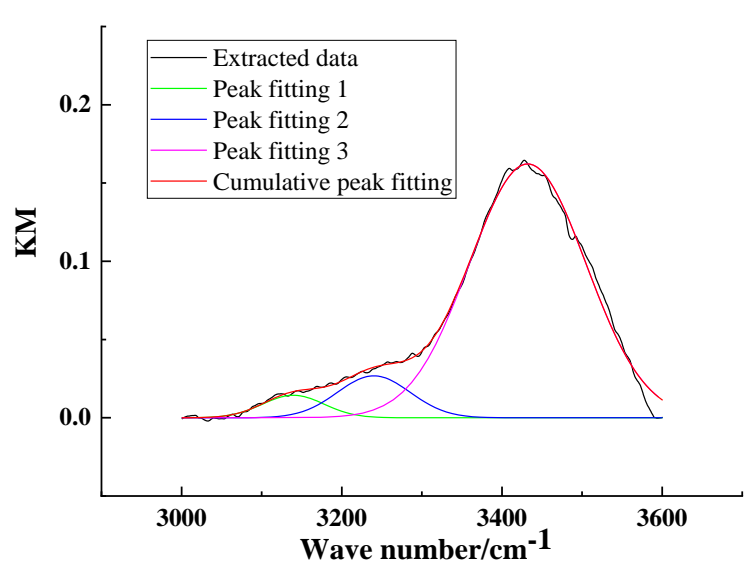

(d) $80^{\circ} \mathrm{C}$ raw coal sample

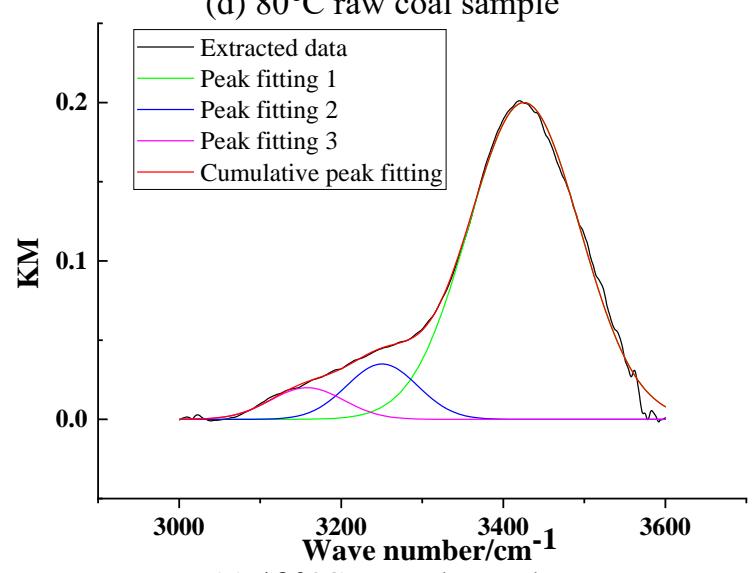

(e) $120^{\circ} \mathrm{C}$ treated sample

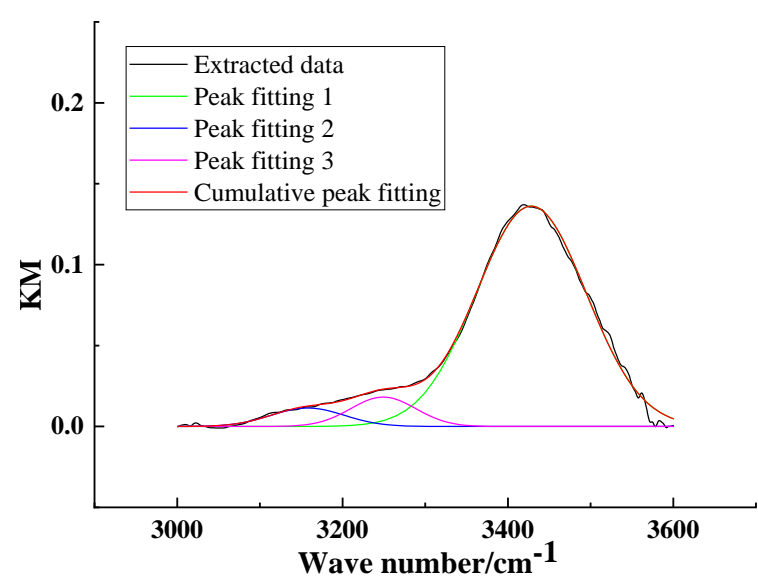

(f) $120^{\circ} \mathrm{C}$ raw coal sample

Figure 11. Fitting of hydroxyl peaks

The strong absorption peaks of the lignite raw coal samples selected for this experiment were phenols, alcohols, ethers and ester-oxygen bonds (Ar-C-O-, 1330 1060) and -COO- (1410, $1590 \sim 1560)$ in the oxygen-containing functional groups, $-\mathrm{CH}_{3}$ and $-\mathrm{CH}_{2}$ in the aliphatic hydrocarbons, $\mathrm{C}=\mathrm{C}$ stretching vibration and $-\mathrm{OH}$ in the aromatic rings. The areas of the absorption peaks of the above major functional group surfaces in the raw coal samples and in the treated samples of highly efficient water-retaining colloidal material at three temperatures are shown in Table 8.

Table 8. Absorption peak areas of functional groups

\begin{tabular}{ccccccc}
\hline \multirow{2}{*}{ Sample } & \multicolumn{7}{c}{ Functional groups } \\
& Ar-C-O- & $-\mathrm{COO}-$ & $-\mathrm{CH}_{3}$ & $-\mathrm{CH}_{2}$ & $\mathrm{C}=\mathrm{C}$ & $-\mathrm{OH}$ \\
\hline $40^{\circ} \mathrm{C}$ raw coal sample & 77.7 & 18.7 & 0.48 & 1.72 & 21.2 & 37.1 \\
$40^{\circ} \mathrm{C}$ treated sample & 81.1 & 19.2 & 0.45 & 1.63 & 23.8 & 44.9 \\
$80^{\circ} \mathrm{C}$ raw coal sample & 66.6 & 15.6 & 0.25 & 0.9 & 20.3 & 22.4 \\
$80^{\circ} \mathrm{C}$ treated sample & 76.9 & 22.3 & 0.65 & 2.06 & 24.2 & 33.6 \\
$120^{\circ} \mathrm{C}$ raw coal sample & 83 & 14.3 & 0.26 & 0.84 & 18.2 & 16.2 \\
$120^{\circ} \mathrm{C}$ treated sample & 78.3 & 21.9 & 0.67 & 2.13 & 23.9 & 28.3 \\
\hline
\end{tabular}

As can be seen from Table 8 , the overall content of each functional group in the treated sample is higher than that in the original coal sample, mainly because the highly efficient water-retaining colloidal material is an organic material, which contains a certain number of functional groups itself. The amount of Ar-C-O- in the raw coal decreases and then increases when the temperature rises, as the oxygencontaining functional groups in the raw coal have started to be oxidised to produce gases such as $\mathrm{CO}$ and $\mathrm{CO}_{2}$; as the temperature rises the water molecules start to evaporate and the amount of $-\mathrm{OH}$ decreases. The Ar-C-O- in the treated samples decreased slightly with increasing coal temperature, but the magnitude of the change was obviously smaller than that of the original coal samples. The highly efficient waterretaining colloidal material inhibited the activity of Ar-C-O-, thus the fluctuation of the functional group content was reduced. evaporation of water and inhibit the oxidative warming process of the coal.

The $\mathrm{C}=\mathrm{C}$ in the original coal sample decreased gradually with increasing temperature, which is due to the low degree of lignite deterioration and the activation of aromatic functional groups even at the low temperature stage, followed by the reaction with oxygen; however, the $\mathrm{C}=\mathrm{C}$ structure in the treated sample did not decrease but slightly increased, which is mainly due to the accumulation of active functional groups in the initial stage of coal oxidation, and the oxidation reaction will occur only when the accumulation reaches the threshold, and $\mathrm{C}=\mathrm{C}$ in the treated samples did not decrease significantly at $120^{\circ} \mathrm{C}$, indicating that the decomposition of the coal structure was delayed backwards at this time.

In addition, the $-\mathrm{CH}_{3}$ and $-\mathrm{CH}_{2}$ content of the raw coal samples was low, but the effect of the highly efficient waterretaining colloidal material on $-\mathrm{CH}_{3},-\mathrm{CH}_{2}$ and -COO- was approximately the same, while the content in the raw coal decreased and the amount in the treated samples increased when the temperature was increased to $80^{\circ} \mathrm{C}$. This is due to the reduction in the number of functional groups in the raw coal as the reactive groups begin to oxidise, while some of the organic molecules contained in the highly efficient waterretaining colloidal material react with the reactive structures in the coal molecules resulting in an increase in the number of functional groups in the treated samples.

In summary, highly efficient water-retaining colloidal materials have a greater influence on the Ar-C-O-, -COO-, $\mathrm{CH}_{3},-\mathrm{CH}_{2}, \mathrm{C}=\mathrm{C}$ stretching vibration and $-\mathrm{OH}$ during the low temperature oxidation of lignite, on the one hand, because highly efficient water-retaining colloidal materials are organic materials will increase the content of functional groups, on the 
other hand, highly efficient water-retaining colloidal materials can also inhibit the activity of several functional groups, thus weakening the oxidation reaction ability of coal molecules, and ultimately The spontaneous combustion of coal is delayed.

\section{CONCLUSION}

(1) By preparing highly efficient water-retaining colloidal material under different dosing ratios of SA, PCC and GDL, the capsule ratio for coal void filling is $2 \% \mathrm{SA}+0.5 \% \mathrm{PCC}+$ $1 \%$ GDL with a molding time of $4.5 \mathrm{~min}$; for extinguishing high temperature fires the capsule ratio is $2.5 \% \mathrm{SA}+1 \% \mathrm{PCC}$ $+1 \%$ GDL with a molding time of $2.5 \mathrm{~min}$.

(2) The highly efficient water-retaining colloidal material slows down the critical temperature and dry cracking temperature of the lignite coal sample, while the pyrolysis temperature and subsequent ignition point temperature and burnout temperature do not change significantly; in addition, it is found that the highly efficient water-retaining colloidal material increases the activation energy of the lignite coal sample in the weight loss and oxygen uptake weight gain stages. Therefore, the highly efficient water-retaining colloidal material has a good inhibiting effect on the oxidation process of coal in the low temperature oxidation stage of coal.

(3) Highly efficient water-retaining colloidal material act as a barrier to chemistry primarily by inhibiting the activity of Ar-C-O-, $-\mathrm{COO}-,-\mathrm{CH}_{3},-\mathrm{CH}_{2}, \mathrm{C}=\mathrm{C}$ stretching vibrations and $\mathrm{OH}$ in the coal structure.

\section{REFERENCES}

[1] Zhang, Y., Yang, C., Li, Y., Huang, Y., Zhang, J., Zhang, Y., Li, Q. (2019). Ultrasonic extraction and oxidation characteristics of functional groups during coal spontaneous combustion. Fuel, 242: 287-294. https://doi.org/10.1016/j.fuel.2019.01.043

[2] Peng, G., Wang, H., Song, X., Zhang, H. (2017). Intelligent management of coal stockpiles using improved grey spontaneous combustion forecasting models. $\quad$ Energy, 132: 269-279. https://doi.org/10.1016/j.energy.2017.05.067

[3] Li, Q.W., Xiao, Y., Zhong, K.Q., Shu, C.M., Lü, H.F., Deng, J., Wu, S. (2020). Overview of commonly used materials for coal spontaneous combustion prevention. Fuel, 275: 117981 https://doi.org/10.1016/j.fuel.2020.117981

[4] Zhao, J., Deng, J., Chen, L., Wang, T., Song, J., Zhang, Y., Zeng, Q. (2019). Correlation analysis of the functional groups and exothermic characteristics of bituminous coal molecules during high-temperature oxidation. Energy, 181: 136-147. https://doi.org/10.1016/j.energy.2019.05.158

[5] Kuenzer, C., Stracher, G.B. (2012). Geomorphology of coal seam fires. Geomorphology, 138(1): 209-222. https://doi.org/10.1016/j.geomorph.2011.09.004

[6] Xue, D., Hu, X., Cheng, W., Wu, M., Shao, Z., Li, Y., Zhang, K. (2020). Carbon dioxide sealing-based inhibition of coal spontaneous combustion: A temperature-sensitive micro-encapsulated fire-retardant foamed gel. Fuel, 266: 117036 https://doi.org/10.1016/j.fuel.2020.117036
[7] Aydin, G., Jang, H., Topal, E. (2016). Energy consumption modeling using artificial neural networks: The case of the world's highest consumers. Energy Sources, Part B: Economics, Planning, and Policy, 11(3): 212-219. https://doi.org/10.1080/15567249.2015.1075086

[8] Peng, G., Wang, H., Song, X., Zhang, H. (2017). Intelligent management of coal stockpiles using improved grey spontaneous combustion forecasting models. $\quad$ Energy, 132: 269-279. https://doi.org/10.1016/j.energy.2017.05.067

[9] Zhao, T., Yang, S., Hu, X., Song, W., Cai, J., Xu, Q. (2020). Restraining effect of nitrogen on coal oxidation in different stages: non-isothermal TG-DSC and EPR research. International Journal of Mining Science and Technology, 30(3): 387-395. https://doi.org/10.1016/j.ijmst.2020.04.008

[10] Onifade, M., Genc, B. (2020). A review of research on spontaneous combustion of coal. International Journal of Mining Science and Technology, 30(3): 303-311. https://doi.org/10.1016/j.ijmst.2020.03.001

[11] Shi, Q.L. (2019). Research on the theory and properties of colloidal foam to prevent spontaneous combustion of coal. China University of Mining and Technology.

[12] Huang, X.H. (2015). Easy to residual coal pillar mining of coal seam spontaneous combustion fire extinguishing technology research.

[13] Lu, X.X. (2016). The prevention and treatment of large space bubble efficient preparation technology and application of coal spontaneous combustion research. China University of Mining and Technology.

[14] Zhang, J., Wagner, W., Prakash, A., Mehl, H., Voigt, S. (2004). Detecting coal fires using remote sensing techniques. International Journal of Remote Sensing, 25(16): 3193-3220. https://doi.org/10.1080/01431160310001620812

[15] Cui, F.S., Laiwang, B., Shu, C.M., Jiang, J.C. (2018). Inhibiting effect of imidazolium-based ionic liquids on the spontaneous combustion characteristics of lignite. Fuel, 217: 508-514. https://doi.org/10.1016/j.fuel.2017.12.092

[16] Feng, X.H., Wang, C.Q., Ding, S.M. (2019). Performance of desulfurization ash for the preparation of grouting fire prevention material. Environmental Science and Pollution Research, 26(19): 19228-19240. https://doi.org/10.1007/s11356-019-05248-1

[17] Feng, X., Wang, C., Ding, S. (2019). Performance of desulfurization ash for the preparation of grouting fire prevention material. Environmental Science and Pollution Research International, 26(19): 19228-19240. https://doi.org/10.1007/s11356-019-05248-1

[18] Yang, Y., Li, Z., Si, L., Hou, S., Zhou, Y., Qi, Q. (2017). Consolidation grouting technology for fire prevention in mined-out areas of working face with large inclined angle and its application. Fire and Materials, 41(6): 700715. https://doi.org/10.1002/fam.2412

[19] Zhang, L., Qin, B. (2014). Development of a new material for mine fire control. Combustion Science and Technology, 186(7): 928-942. https://doi.org/10.1080/00102202.2014.890600

[20] Wang, D.M. (2004). A new technology of three-phase foam for mine fire control. Safety in Coal Mine, 35(7), 16-18. 
[21] Qin, B.T., Wang, D.M., Chen, J.H., Liang, X.Y. (2005). Experimental investigation of high-performance threephase foam for mine fire control. Journal of China University of Mining and Technology, 34(1): 11-15. https://doi.org/10.3321/j.issn:1000-1964.2005.01.003

[22] Wang, T., Fan, H., Yang, W., Meng, Z. (2020). Stabilization mechanism of fly ash three-phase foam and its sealing capacity on fractured reservoirs. Fuel, 264: 116832. https://doi.org/10.1016/j.fuel.2019.116832

[23] Baohua, T. (2011). Three-phase foam fight fire technology in the coal mine study. Energy Procedia, (11): 3720-3725. https://doi.org/10.1016/j.egypro.2011.10.750

[24] Hao, Y., Xie, T. (2021). Coupling treatment of gas drainage and nitrogen injection for fire prevention in the first stratified mining goaf: Theoretical calculation and field experiment. Combustion Science and Technology, 1-15. https://doi.org/10.1080/00102202.2021.1895774

[25] Shi, G.Q., Ding, P.X., Guo, Z., Wang, Y.M. (2019). Modeling temperature distribution upon liquid-nitrogen injection into a self heating coal mine goaf. Process Safety and Environmental Protection, 126: 278-286. https://doi.org/10.1016/j.psep.2019.03.033

[26] Jia, Y.W. (2013). Research on nitrogen inerting explosion suppression technology in mining areas, Liaoning University of Engineering and Technology.

[27] Zhai, X.W., Yang, C., Shi, B.B., Ge, H., Wu, S.B. (2021). Inhibition performance of microcapsule material on coal oxidation. Journal of Thermal Analysis and Calorimetry, 1-13. https://doi.org/10.1007/s10973-021-10584-X

[28] Fan, S., Wen, H., Zhang, D., Yu, Z. (2019). Experimental research on the performance of the macromolecule colloid fire-extinguishing material for coal seam spontaneous combustion. Advances in Materials Science and Engineering, 2019: 6940985. https://doi.org/10.1155/2019/6940985

[29] Jin, Y.F., Yan, L., Zhang, D., Cheng, M. (2020). Study on the optimized ratio of cured filling materials of fire prevention foam cement for mining. Journal of Safety and Environment, 20(5): 1743-1751. https://doi.org/10.13637/j.issn.1009-6094.2019.1008

[30] Yang, G.J. (2011). Experimental study on the damping performance of coal spontaneous combustion aerosols, Xi'an University of Science and Technology. https://doi.org/10.7666/d.d156172
[31] Zhang, L.L. (2014). Research on gel foam and properties to prevent spontaneous combustion of coal, China University of Mining and Technology.

[32] Huang, W., Zhao, L., Zhang, J., Wen, H., Zhu, Z., Wang, P., Liu, C. (2021). Template-etched sodium alginate hydrogel as the sublayer to improve the FO performance with double barriers for high metal ion rejection. Chemical Engineering Journal, 413: 127425. https://doi.org/10.1016/j.cej.2020.127425

[33] Zheng, J., Zeng, R., Zhang, F., Kan, J. (2019). Effects of sodium carboxymethyl cellulose on rheological properties and gelation behaviors of sodium alginate induced by calcium ions. LWT, 103: 131-138. https://doi.org/10.1016/j.lwt.2018.12.081

[34] Guo, J., Wen, H., Zheng, X., Liu, Y., Cheng, X. (2019). A method for evaluating the spontaneous combustion of coal by monitoring various gases. Process Safety and Environmental Protection, 126: 223-231. https://doi.org/10.1016/j.psep.2019.04.014

[35] Liu, Y., Wen, H., Guo, J., Jin, Y., Wei, G., Yang, Z. (2020). Coal spontaneous combustion and $\mathrm{N}_{2}$ suppression in triple goafs: A numerical simulation and experimental study. Fuel (Guildford), 271: 117625. https://doi.org/10.1016/j.fuel.2020.117625

[36] Cao, J., Ma, Y. (2019). Pyrolysis and gasification of macroalgae Enteromorpha prolifera under a $\mathrm{CO}_{2}$ atmosphere using the thermogravimetry-Fourier transform infrared spectroscopy technique. Progress in Reaction Kinetics and Mechanism, 44(2): 132-142. https://doi.org/10.1177/1468678319825735

[37] Jakab, E., Mészáros, E., Borsa, J. (2010). Effect of slight chemical modification on the pyrolysis behavior of cellulose fibers. Journal of Analytical and Applied Pyrolysis, $\quad 87(1)$ : 117-123. https://doi.org/10.1016/j.jaap.2009.10.012

[38] Kaci, M., Aouat, T., Devaux, E., Lopez-Cuesta, J.M. (2019). The effects of filler size and content on the fire behavior of melt-spun poly (lactic acid)/cellulose bionanocomposite fibers. In AIP Conference Proceedings, 2196(1): 020017. https://doi.org/10.1063/1.5140290

[39] Li, R., Luo, Z., Wang, T., Cheng, F., Lin, H., Zhu, X. (2020). Effect of initial temperature and $\mathrm{H}_{2}$ addition on explosion characteristics of $\mathrm{H}_{2}$-poor/ $\mathrm{CH}_{4}$ /air mixtures. Energy, 213: 118979. https://doi.org/10.1016/j.energy.2020.118979 